\title{
Web-Site-Based Tailored Advice to Promote Strength and Balance Training: An Experimental Evaluation
}

\author{
Samuel R. Nyman and Lucy Yardley
}

\begin{abstract}
This study evaluated a Web site providing tailored advice to encourage older people to undertake strength and balance training (SBT). Adults age 60-88 $(N=302)$ were randomized to read either generic advice or advice tailored to their self-perceived balance problems and activity preferences. Between-groups differences in attitudes toward SBT after reading the advice did not quite reach significance $(p=.059)$, but the tailored group reported higher ratings than the generic group that the advice was personally relevant $(p=.017)$ and that the activities would be good for them $(p=$ .047). Within-groups differences in the tailored group showed that completing an action plan increased confidence in undertaking SBT $(p=.006)$. These findings were supported by a meta-analysis that pooled the effect sizes with those of a previous study. Thus, a tailored Web site might be a cost-effective way of encouraging some older people to undertake SBT.
\end{abstract}

Keywords: falls, Internet, older people, prevention

Falls are widely recognized as a major cause of morbidity and mortality in older people. One in three people age 65 and over suffers a fall each year, and of these $20-30 \%$ become less mobile and more at risk for premature death (Skelton \& Todd, 2004). There is evidence that the incidence of falls can be reduced if older people regularly carry out strength and balance training (SBT; Skelton \& Todd), physical activities that enhance balance, coordination, and lower leg muscle strength (Chang et al., 2004). Individualized SBT exercise interventions in particular have been shown to reduce falls, but they are resource intensive and so might only be a cost-effective option for those most at risk for falling (Chang et al.; Gillespie et al., 2003). Because younger, more active older adults also suffer from injurious falls (Speechley \& Tinetti, 1991), there is a need to promote SBT to the wider population of community-dwelling older people cost-effectively (Chang et al.; Skelton \& Todd).

This article presents the evaluation of a Web-site-based intervention developed as a new resource for older people to encourage them to undertake SBT. The Web-site advice was tailored, in that it selectively presented advice to individuals

Nyman is with the Inst. of Health Sciences, University of Reading, Reading, RG1 5AQ, UK. Yardley is with the School of Psychology, University of Southampton, Southampton, UK. 
based on their answers to closed-ended questions (Kreuter, Farrell, Olevitch, \& Brennan, 2000). Tailored advice is in theory more persuasive because it is more personally relevant (Petty \& Cacioppo, 1981), but recent evidence for using tailored physical activity advice is mixed (Hurling et al., 2007; Kroeze, Werkman, \& Brug, 2006; Vandelanotte, De Bourdeaudhuij, Sallis, Spittaels, \& Brug, 2005; Williams et al., 2006).

To our knowledge, our Web site is the first to use tailoring to present advice to older people on preventing falls. We identified two published articles on a previous Web site that provided advice on preventing falls, but that Web site did not use tailoring as defined by Kreuter and Skinner (2000). The first version of the Web site presented 20 scenarios of how others have prevented falls, but these were not personally relevant to many users (Ezendam, Alpay, Rövekamp, \& Toussaint, 2005). The second version of the same Web site was more interactive but only contained one optional health-appraisal section that used tailoring, and this version has yet to be evaluated (Alpay et al., 2007).

The aim of this study was to compare older people's attitudes toward undertaking SBT activities after receiving one of two versions of Web-site advice: either tailored (intervention) or generic (control). An evaluation of an earlier version of the Web site found that those randomly assigned to the tailored version reported significantly higher scores for the advice being personally relevant and greater confidence and intention to undertake SBT (Yardley \& Nyman, 2007). However, limitations of the previous study were that a validated scale was not used for the outcome measures, and the sample was older and frailer than the population we had targeted. For the current study we used a validated scale for the outcome measures and recruited a younger sample of older adults. We hypothesized that participants who received the tailored advice would perceive it to be more personally relevant and report more positive attitudes toward undertaking SBT than participants who received the generic advice. The tailored group also completed an action plan, and we hypothesized that they would report greater confidence and intention to undertake SBT after completing the plan.

\section{Methods}

\section{Design and Procedure}

We used a cross-sectional between-groups design, randomizing participants to either tailored (intervention) or generic (control) Web-site SBT advice. After reading the advice, both groups completed an online questionnaire. After this betweengroups comparison, a within-group experiment was carried out in the tailored group only. After completing the questionnaire, the tailored group went on to complete an action plan and a further questionnaire, providing a comparison of pre- and post-action-plan scores.

\section{Web-Site Intervention}

The earlier version of the Web site (Yardley \& Nyman, 2007) was amended to improve its usability and the appropriateness of the advice based on the findings of a qualitative study (Nyman \& Yardley, in press). The Web site was available 
online at www.balancetraining.org.uk. It first provided a definition of SBT and explained why it can benefit people of all ages, especially those with balance problems. The next page informed users that they would be randomized to receive either tailored or generic advice and requested informed consent to collect data. The Web site then automatically randomized participants to the tailored- or generic-advice groups according to whether the exact time they clicked to provide consent ended in an odd or even number. This allowed for blind and concealed randomization to conditions. In both groups the outcome measures were administered at the end of the pages on which the advice was presented. Participants entered their responses directly into boxes on the Web site, which were recorded when the participant clicked on the submit button that advanced them to the next page. Data were automatically recorded into a Microsoft Office Excel 2003 spreadsheet that was available online to the researchers and was password protected.

Tailored Web Pages. The first part of the tailored pages consisted of questions used to elicit demographic data and to tailor the advice. Initially, feedback was provided on whether the participant was currently carrying out the recommended level of SBT. In the first version of the Web site this feedback was only available to those who self-rated their balance as good and wanted to keep it that way, but for this version it was made available to everyone in the tailored group. Current SBT activity was measured by agreement with up to four statements indicating that they were currently carrying out physical activity that included moderately strenuous physical activity for a minimum of $150 \mathrm{~min} /$ week, exertion of lower leg muscles, quick movements of the head and body several times a week, and activities involving balancing and coordinating eye, head, and body movements more than once a week. Feedback praised current SBT activity and highlighted areas for improvement. A new advice and tips section was also presented in relation to four concerns about undertaking SBT (not having time and that SBT is too strenuous, might cause an injury, or is too expensive). Self-rated balance ("my balance is good and I want to keep it that way"; "my balance is quite good, but I would like to improve it"; and "I have some problems with balance that I want to overcome") and preferences for where the activity was carried out (at home, outside the home, in a group or class) were used to select a menu of advice about suitable activities and how these could contribute to improving balance. The most challenging activities (jogging, cycling, sports, and going to the gym) were only recommended to those who indicated that their balance was good, and advice to reduce hazards around the home was only given to those who indicated that they had balance problems. SBT exercises carried out at home or in a class, walking, and Tai Chi were recommended for all levels of self-rated balance but were presented differently to the different groups (e.g., regarding how strenuous the activity should be). Participants then selected their preferred activities from a list of suggested activities. Final personalized recommendations consisted of an explanation of how each kind of activity they had selected would improve their balance (e.g., either by strengthening the legs or by improving coordination) and additional advice relating to their particular health conditions known to be associated with an increased risk of falls (e.g., poor vision and taking four or more types of daily medications; see Table 1).

After the postadvice questionnaire was presented to compare intervention participants' reports with those of the generic group, participants were asked to 


\section{Table 1 Gender, Self-Rated Balance, and Health Condition $(N=302)$}

\begin{tabular}{lc}
\hline & Frequency (\%) \\
\hline Gender & $115(38)$ \\
male & $187(62)$ \\
female & \\
Self-rated balance & $101(33)$ \\
good & $86(29)$ \\
quite good & $115(38)$ \\
have some problems & \\
Health condition & $108(36)$ \\
unsteadiness & $17(6)$ \\
poor vision & $36(12)$ \\
osteoporosis & $75(25)$ \\
take $\geq 4$ medications & $110(36)$ \\
take $<4$ medications & $117(39)$ \\
take no medication & $62(21)$ \\
dizziness when getting up quickly & $19(6)$ \\
dizziness when rolling over in bed & $26(9)$ \\
dizziness when shaking or nodding head & $8(3)$ \\
dizziness most of the time & $41(14)$ \\
dizziness in unexpected spells &
\end{tabular}

Note. There was no significant difference between the tailored and generic strength-and-balancetraining-advice groups as a function of age, gender, self-rated balance, or health condition, so only the combined totals are presented.

complete an action plan detailing when and where they would carry out their main SBT activity, when they would start their plan, and who would encourage them to carry out their plan. A questionnaire was then presented to allow a within-group comparison in the tailored group of scores before and after completing the action plan. The final page debriefed participants.

Generic Web Pages. The content of the generic pages was derived from the tailored pages, and the presentation format was similar. First the demographic and health-related variables were assessed, and then all the advice from which the tailored advice was selected was presented, grouped into meaningful categories (e.g., "balance-training exercises that you can do at home," "improving balance while getting out and about"). The description of each activity was followed by an explanation of how it would contribute to improving balance and the advice relating to all the health conditions. The questionnaire was presented and then the debriefing page.

\section{Outcome Measures}

The outcome measure for the between-groups comparison was based on the Attitudes to Falls-Related Interventions Scale (AFRIS; Prevention of Falls Network Europe, 2006). The AFRIS was developed from views of falls prevention expressed 
in a qualitative study (Yardley et al., 2006) and was validated in a study in which it was a strong predictor of intention to carry out SBT (Yardley, Donovan-Hall, Francis, \& Todd, 2007). It is based on the theory of planned behavior (Ajzen, 1988, 1991), which has been found to be useful in predicting older people's strength-training behavior (Dean, Farrell, Kelley, Taylor, \& Rhodes, 2007). The AFRIS comprises six items measuring five constructs: intention to carry out the recommended activities, perceived behavioral control (PBC; confidence in ability to do the recommended activities), attitude (two items: belief that the recommended activities will be good for them and make them feel confident), subjective norm (belief that other people whose opinions matter to them would think it was a good idea for them to do the recommended activities), and identity (belief that they are the kind of person who should do the recommended activities). An item was added to the six-item AFRIS for this study to assess the personal relevance of the recommended activities. All seven items were scored from 1 (disagree strongly) to 7 (agree strongly), with a minimum and maximum total score of 7 and 49, respectively.

For the pre- and post-action-plan within-group comparison, participants receiving the tailored advice completed just the $\mathrm{PBC}$ and intention items again after completing the action plan. PBC was included because goal theory and behavioral/contingency contract theory predict that such action plans increase confidence to undertake an activity (Bandura, 1997; Janz, Becker, \& Hartman, 1984; Kanfer \& Gaelick, 1986; Locke \& Latham, 1990). Intention was also included because an increase in intention might be associated with an increase in PBC (Ajzen, 1988, 1991), but the action plan was unlikely to affect the other variables of the AFRIS (attitude, subjective norm, or identity).

\section{Participants}

Before recruitment commenced, the study was approved by the ethics committee of the School of Psychology, University of Southampton. Participants were recruited both impersonally and in person. Impersonal methods were advertisements on Web sites, in a participant pool newsletter, university news bulletin, and on a broadcast sent to two e-mail distribution lists to health care professionals working with older people in the National Health Service or freelance, plus members from organizations with an interest in falls and health. In person, the first author advertised the study at branch meetings of the University of the Third Age, social clubs, and other recreational places that older people frequent. Participants' data were included if they indicated that they were at least 60 years old and had accessed the Web site for themselves. For participants who accessed the Web site more than once, only their first data set was included.

\section{Data Analysis}

To test the first hypothesis, a between-groups analysis of variance (ANOVA) was performed between the tailored and generic groups on the total score of the seven summed items (AFRIS plus personal relevance), and a between-groups multivariate ANOVA (MANOVA) was performed on the seven items individually. To test the second hypothesis, a within-group MANOVA was performed with the tailored 
group only on the two dependent variables (PBC and intention) measured before and after completing the action plan.

Data were collected over 7 months (September 2006 to April 2007), until the minimum number of participants had been recruited for a desired power value of .80 , with a one-tailed hypothesis and an alpha level of .05 . The minimum sample size was 276 participants (138 per group), calculated from the means and standard deviations for intention to undertake SBT activities from the previous Web-site evaluation (Yardley \& Nyman, 2007).

Tests were performed to determine whether the data met parametric assumptions of ANOVAs and MANOVAs. The cell sizes were deemed large enough to provide robustness to the modest negative skew and kurtosis identified on each dependent variable, but because MANOVAs are sensitive to outliers (Pallant, 2001), 15 multivariate outliers that were identified from a Mahalanobis distances test were removed for the between-groups MANOVA (seven from the tailored group and eight from the generic group), and two more were removed for the repeated-measures MANOVA. A sensitivity analysis on the between-groups MANOVA before and after removing the 15 multivariate outliers is reported in the Results section.

In addition to the tests of the hypotheses, a meta-analysis was performed to combine the results from this study with those of the similar previous study evaluating the first version of the Web site (Yardley \& Nyman, 2007). To test the efficacy of tailoring (tailored vs. generic between-groups test), the total score on the dependent variables from the current study was pooled with the combined dependent variable of the MANOVA from the earlier study, which combined six similar self-report items evaluating the advice. To test the efficacy of the action plan on the tailored group (pre- vs. post-action plan within-group test), the combined dependent variable of the MANOVA from the current study was pooled with a similar MANOVA-combined dependent variable from the earlier study that was not previously reported. The pooled effect sizes were calculated by converting the eta $(\eta)$ values into $z$ scores $\left(z_{\mathrm{r}}\right)$, averaging them, and then converting them to Pearson's $r$ values (Howitt \& Cramer, 2000). The pooled significance levels were calculated by converting the $p$ values to $z$ scores, dividing them by the square root of the number of studies, and then converting them back to $p$ values (Howitt \& Cramer).

\section{Results}

\section{Participant Characteristics}

The number of participants who advanced through the Web site and completed the postadvice questionnaire was 302 (157 tailored group, 145 generic group). For the number of participants who dropped out before filling in the postadvice questionnaire $(n=133,31 \%)$, there was no significant difference in dropout rate between the tailored $(n=65,15 \%)$ and generic groups $(n=68,16 \%)$. Participants were $60-88$ years of age $(M=70.41, S D=7.07)$, and there was no significant difference between the tailored and generic groups in age, gender, self-rated balance, or health conditions. Two thirds of the participants were women, and there was an 
even spread of self-rated balance. Two thirds of the participants were taking medication, one third reported suffering from unsteadiness, and one quarter reported suffering from dizziness when getting up quickly (see Table 1).

Data were available for the tailored group's $(n=157)$ inputs into the interactive sections of the Web site. The section on current SBT activity indicated a low level of activity, with only $9(5.5 \%)$ participants indicating that they were currently engaged in the frequency, duration, and intensity of SBT required to improve their balance. Those currently engaged in more SBT activity were found to report more positive attitudes toward the SBT advice, but the effect of tailoring was not moderated by current level of SBT activity. The section on concerns about undertaking SBT was underused; three quarters of participants were not in agreement with any of the four concerns presented $(n=121,77 \%)$, with the remaining in agreement with either one $(n=31,20 \%)$ or two statements $(n=5,3 \%)$ indicating a concern. "Only at home" was the most preferred location for carrying out SBT activities $(107,68 \%)$, compared with solely outside $(41,26 \%)$ or solely in a class $(23,15 \%)$. Exercises at home $(70,46 \%)$ and walking $(34,22 \%)$ were the two most preferred main activities. Of the 31 goals that were reported, the two most frequently reported were "to improve health or fitness" $(n=41,31 \%)$ and to "improve confidence in balance" $(n=16,12 \%)$, either generally or with a specific task or activity.

\section{Comparison of Tailored and Generic SBT Advice}

The AFRIS had a Cronbach's alpha value of .88 , which increased to .90 when the item assessing personal relevance was included, confirming reliability. The oneway between-groups ANOVA found a marginally nonsignificant difference on the total score as a function of advice condition, $F(1,300)=3.58, p=.059$, partial $\eta^{2}$ $=.012$. Univariate effects of a one-way between-groups MANOVA $(N=287)$ revealed that there was a significant difference between the advice conditions on participants' perceived personal relevance of the recommended activities, $F(1$, $285)=5.81, p=.017$, partial $\eta^{2}=.020$, and reports that the recommended activities would be good for them, $F(1,285)=4.00, p=.047$, partial $\eta^{2}=.014$. As suggested by the means presented in Table 2, the tailored group reported higher scores than the generic group on reports that the advice was personally relevant and that the recommended activities would be good for them. The tailored group also reported more positively than the generic group on the other five dependent variables, but not significantly. Sensitivity analysis with the 15 multivariate outliers included $(N=302)$ yielded a similar result for the univariate effect for personal relevance, $F(1,300)=7.09, p=.008$, partial $\eta^{2}=.023$. However, the tailored group no longer reported a significantly greater belief than the generic group that the recommended activities would be good for them, $F(1,300)=2.30, p=.130$, partial $\eta^{2}=.008$.

\section{Intention and Confidence Before and After Completing an Action Plan}

Because 26 participants did not complete the post-action-plan questionnaire and nine outliers were removed, the repeated-measures MANOVA was performed on 
122 participants in the tailored group. A significant difference was found on the combined dependent variable, $F(2,120)=3.88, p=.023$, Pillai's trace $=.061$, and the within-group contrasts revealed that $\mathrm{PBC}$ was significantly higher after completing an action plan, $F(1,121)=7.83, p=.006$, partial $\eta^{2}=.061$, but no significant difference was found for intention, $F(1,121)=.81$, n.s., partial $\eta^{2}=.007$ (see Table 3).

\section{Meta-Analysis}

Pooling the current study with the evaluation of the previous version of the Web site (Yardley \& Nyman, 2007) provided a sample of 582 adults (301 tailored group, 281 generic group) age $60-97$ years $(M=73.83, S D=7.09)$. The betweengroups pooled effect was significant in favor of tailored over generic advice $(r=$ $.18, p=.01)$, and the within-group pooled effect with the tailored group $(n=235)$ found the action plan to significantly increase the persuasiveness of the advice $(r$ $=.24, p=.001)$.

Table 2 Reports After Strength-and-Balance-Training Advice as a Function of Advice Condition ( $N=287)$

\begin{tabular}{lccc}
\hline Item & $\begin{array}{c}\text { Tailored }(\boldsymbol{n}= \\
\mathbf{1 5 0}), \boldsymbol{M} \pm \mathbf{S} \boldsymbol{D}\end{array}$ & $\begin{array}{c}\text { Generic }(\boldsymbol{n}= \\
\mathbf{1 3 7}), \boldsymbol{M} \pm \mathbf{S} \boldsymbol{D}\end{array}$ & $\begin{array}{c}\mathbf{9 5 \%} \text { CI for the between- } \\
\text { groups difference }\end{array}$ \\
\hline $\begin{array}{l}\text { Personally relevant } \\
\text { Would be good for me }\end{array}$ & $5.87 \pm 0.79$ & $5.64 \pm 0.78$ & $.041, .408$ \\
$\quad \begin{array}{l}\text { Would give me } \\
\quad \text { confidence }\end{array}$ & $5.69 \pm 0.70$ & $5.93 \pm 0.64$ & $.002, .316$ \\
$\quad \begin{array}{l}\text { Others would think it was } \\
\text { good }\end{array}$ & $5.79 \pm 0.81$ & $5.65 \pm 0.87$ & $-.087, .325$ \\
$\quad \begin{array}{l}\text { Would be easy to do } \\
\text { I should do the activities }\end{array}$ & $5.68 \pm 0.89$ & $5.64 \pm 0.96$ & $-.072, .317$ \\
$\quad \begin{array}{l}\text { I intend to do the } \\
\quad \text { activities }\end{array}$ & $5.84 \pm 0.76$ & $5.69 \pm 0.88$ & $-.170, .260$ \\
$\quad$ Total & $5.83 \pm 0.73$ & $5.73 \pm 0.75$ & $-.037, .345$ \\
\hline
\end{tabular}

Note. $\mathrm{CI}=$ confidence interval. Items were scored from $1=$ disagree strongly to $7=$ agree strongly; total scores ranged from 7 to 49 .

Table 3 Perceived Behavioral Control and Intention to Undertake Strength and Balance Training in the Tailored Group Before and After Completing an Action Plan $(N=122)$

\begin{tabular}{lccc}
\hline Item & $\begin{array}{c}\text { Before, } \\
\boldsymbol{M} \pm \mathbf{S D}\end{array}$ & $\begin{array}{c}\text { After, } \\
\boldsymbol{M} \pm \mathbf{S D}\end{array}$ & $\begin{array}{c}\mathbf{9 5 \%} \text { Cl for the } \\
\text { difference }\end{array}$ \\
\hline Perceived behavioral control & $5.73 \pm 0.84$ & $5.87 \pm 0.76$ & $-.238,-.041$ \\
Intention & $5.86 \pm 0.71$ & $5.90 \pm 0.72$ & $-.131, .049$ \\
\hline
\end{tabular}

Note. $\mathrm{CI}=$ confidence interval. Items were scored from $1=$ disagree strongly to $7=$ agree strongly. 


\section{Discussion}

Although trained staff are required to provide older people at high risk of falling with specialist advice on how to manage their risk of falls, all older people could be made more aware of the benefits of SBT and be encouraged to participate in SBT activities. This study evaluated a Web site designed to provide communitydwelling older people with advice to encourage them to undertake SBT. In partial support of the first hypothesis, compared with generic advice, tailored advice was associated with greater perceived personal relevance of the recommended SBT activities and greater perception that the recommended SBT activities would be good for them. However, the tailored group's greater perception that the recommended SBT activities would be good for them was only significant when the multivariate outliers were excluded. In partial support of the second hypothesis, an action plan increased the tailored group's confidence in carrying out SBT. In addition, the meta-analysis of this study with a previous study (Yardley \& Nyman, 2007) indicated that older people might report more positive attitudes toward undertaking SBT activities after receiving tailored motivational advice and after completing an action plan. Although the effect sizes were small, a small effect size can make a useful contribution to the population's health using low-cost interventions readily available to the general public.

Our study adds to the literature on tailoring that to date has found mixed evidence of the efficacy of tailoring advice in positively influencing attitudes toward undertaking physical activity (Bull, Holt, Kreuter, Clark, \& Scharff, 2001; Calfas et al., 2002; Cardinal \& Sachs, 1995; Hageman, Noble Walker, \& Pullen, 2005; Hurling et al., 2007; Hurling, Fairley, \& Dias, 2006; Kreuter, Bull, Clark, \& Oswald, 1999; Kreuter, Oswald, Bull, \& Clark, 2000; Vandelanotte \& De Bourdeaudhuij, 2003). The action plan increased confidence but not intention to undertake SBT. Action plans have been found to increase confidence by helping prepare for performing a behavior and anticipating and solving problems (Bandura, 1997; Janz et al., 1984; Kanfer \& Gaelick, 1986; Locke \& Latham, 1990). However, a significant increase in intention after completing an action plan was less likely, because participants would be expected to have already decided whether they would undertake the recommended balance-training activities. Nevertheless, an increase in confidence can increase the likelihood that a person will adopt a new behavior (Ajzen, 1988, 1991).

The previous evaluation of the first version of the Web site found a larger positive association between tailoring and confidence and intention to undertake SBT activities (Yardley \& Nyman, 2007). One possible explanation for this finding is that because most participants in that study were recruited through personal contact with the researcher, they might have been more inclined to rate the Web site positively whichever group they were in, resulting in less variance in the data to show an effect of tailoring. In contrast, in the previous study a measure of attitude ("I believe that the activities will improve my balance if I carry them out") was not significantly more positive in the tailored group but was in the more general measure of attitude used in the current study ("Doing the recommended activities would be good for me"). 


\section{Study Limitations and Recommendations for Future Research}

Because we did not measure participants' attitudes toward SBT activities before they received the advice, it was not possible to calculate treatment effects and reliably conclude that the difference between groups postintervention was caused by tailoring the advice. Future research could collect baseline data and calculate changes between groups over time. As in the previous study (Yardley \& Nyman, 2007), the current study had a ceiling effect for each rating of the SBT advice. This might have been because the participants generally found the advice to be acceptable. Alternatively, because the samples were self-selected, most participants who took part and remained to give their ratings on the advice might have already held positive attitudes toward it. Further research is therefore required to determine whether the tailored advice is persuasive among those who hold neutral or negative attitudes toward SBT.

In using the Internet, the intervention will not reach all older people, so other formats will be required. However, the Web-site-based SBT advice might well be useful to those working with or caring for older people who could help them access the Web site or who could access the Web site on an older person's behalf (Nyman \& Yardley, in press).

To reduce participant dropout we used a very brief outcome measure, the AFRIS. The AFRIS uses only single-item measures of each component of the theory of planned behavior, and these are therefore likely to have had limited reliability and sensitivity. More comprehensive measures and qualitative methods could be used to ascertain the impact of tailored advice on older people's attitudes toward SBT activities (Kreuter, Farrell, et al., 2000). This study was only able to assess attitudes and intentions toward carrying out SBT. Intentions have been shown to predict behavior (Webb \& Sheeran, 2006), but behavior is also influenced by additional factors such as the environment (e.g., transport, expense, social support), skills, and personality. Further research is required to determine whether Web-site-based advice on falls prevention needs to be supplemented by other forms of support and whether it does change behavior, using validated selfreport and objective measures of physical activity (Jørstad-Stein et al., 2005).

\section{Conclusion}

This study compared older people's attitudes toward undertaking SBT after receiving either tailored or generic advice. The tailored motivational advice was associated with reports of greater personal relevance and greater perceived benefit of SBT activities. In addition, completing an action plan increased confidence to undertake SBT. These findings were supported by a meta-analysis with a previous study and suggest that tailored SBT advice might be a cost-effective means of encouraging older people to regularly carry out SBT activities. However, this format will not be suitable for all older people, and further research is required assessing attitudes before and after receiving tailored advice to reliably conclude 
whether tailoring is more efficacious than generic advice and to assess the effect of tailored advice on actual uptake of SBT activities.

\section{Acknowledgments}

This study was partly funded by a PhD studentship from the Economic and Social Research Council, UK, awarded to the first author while he was at the University of Southampton. We thank Mario Mohammed and James Durrant (RioMed) for developing the Web site, Pamela Holmes and Cheryl Blake (Help the Aged, UK) for commenting on and advertising the Web site, and members of the Prevention of Falls Network Europe (ProFaNE) for checking the safety and appropriateness of the advice on the Web site. We thank webmasters; those in charge of local clubs, groups, and organizations; and others who promoted the Web site for their assistance with recruitment and the older people for their participation. We also thank the two anonymous reviewers for their helpful comments.

\section{References}

Ajzen, I. (1988). Attitudes, personality, and behavior. Milton Keynes, UK: Open University Press.

Ajzen, I. (1991). The theory of planned behavior. Organizational Behavior and Human Decision Processes, 50, 179-211.

Alpay, L., Toussaint, P., Ezendam, N., Rövekamp, T., Westendorp, R., Verhoef, J., et al. (2007). The Dutch Website: "SeniorGezond": An illustration of a road map for the informed patient. Managed Care (Langhorne, Pa.), 2, 1-11.

Bandura, A. (1997). Self-efficacy: The exercise of control. New York: W.H. Freeman \& Co.

Bull, F.C., Holt, C.L., Kreuter, M.W., Clark, E.M., \& Scharff, D. (2001). Understanding the effects of printed health education materials: Which features lead to which outcomes? Journal of Health Communication, 6, 265-279.

Calfas, K.J., Sallis, J.F., Zabinski, M.F., Wilfley, D.E., Rupp, J., Prochaska, J.J., et al. (2002). Preliminary evaluation of a multicomponent program for nutrition and physical activity change in primary care: PACE+ for adults. Preventive Medicine, 34, 153-161.

Cardinal, B.J., \& Sachs, M.L. (1995). Prospective analysis of stage-of-exercise movement following mail-delivered, self-instructional exercise packets. American Journal of Health Promotion, 9, 430-432.

Chang, J.T., Morton, S.C., Rubenstein, L.Z., Mojica, W.A., Maglione, M., Suttorp, M.J., et al. (2004). Interventions for the prevention of falls in older adults: Systematic review and meta-analysis of randomised clinical trials. British Medical Journal, 328, 680683.

Dean, R.N., Farrell, J.M., Kelley, M.L., Taylor, M.J., \& Rhodes, R.E. (2007). Testing the efficacy of the theory of planned behavior to explain strength training in older adults. Journal of Aging and Physical Activity, 15, 1-12.

Ezendam, N.P.M., Alpay, L.L., Rövekamp, T.A.J.M., \& Toussaint, P.J. (2005). Experimenting with case-based reasoning to present educative health information on the internet: The example of SeniorGezond. Studies in Health Technology and Informatics, 116, 867-872.

Gillespie, L. D., Gillespie, W. J., Robertson, M. C., Lamb, S. E., Cumming, R. G., \& Rowe, B. H. (2003). Interventions for preventing falls in elderly people. Cochrane Database of Systematic Reviews, 4, Art. No. CD000340-DOI: 10.1002/14651858.CD000340.

Hageman, P.A., Noble Walker, S., \& Pullen, C.H. (2005). Tailored versus standard Internetdelivered interventions to promote physical activity in older women. Journal of Geriatric Physical Therapy, 28, 29-34. 
Howitt, D., \& Cramer, D. (2000). An introduction to statistics in psychology: A complete guide for students (2nd ed.). London: Prentice Hall.

Hurling, R., Catt, M., De Boni, M., Fairley, B.W., Hurst, T., Murray, P., et al. (2007). Using Internet and mobile phone technology to deliver an automated physical activity program: Randomized controlled trial. Journal of Medical Internet Research, 9, e7.

Hurling, R., Fairley, B.W., \& Dias, B. (2006). Internet-based exercise intervention systems: Are more interactive designs better? Psychology \& Health, 21, 757-772.

Janz, N.K., Becker, M.H., \& Hartman, P.E. (1984). Contingency contracting to enhance patient compliance: A review. Patient Education and Counseling, 5, 165-178.

Jørstad-Stein, E.C., Hauer, K., Becker, C., Bonnefoy, M., Nakash, R.A., Skelton, D.A., et al. (2005). Suitability of physical activity questionnaires for older adults in fallprevention trials: A systematic review. Journal of Aging and Physical Activity, 13, 461-481.

Kanfer, F.H., \& Gaelick, L. (1986). Self-management methods. In F.A. Kanfer \& A.P. Goldstein (Eds.), Helping people change: A textbook of methods (3rd ed., pp. 283345). Oxford: Pergamon Press.

Kreuter, M.W., Bull, F.C., Clark, E.M., \& Oswald, D.L. (1999). Understanding how people process health information: A comparison of tailored and nontailored weight-loss materials. Health Psychology, 18, 487-494.

Kreuter, M.W., Farrell, D., Olevitch, L., \& Brennan, L. (2000). Tailoring health messages: Customizing communication with computer technology. Mahwah, NJ: Lawrence Erlbaum.

Kreuter, M.W., Oswald, D.L., Bull, F.C., \& Clark, E.M. (2000). Are tailored health education materials always more effective than non-tailored materials? Health Education Research, 15, 305-315.

Kreuter, M.W., \& Skinner, C.S. (2000). Tailoring: What's in a name? Health Education Research, 15, 1-4.

Kroeze, W., Werkman, A., \& Brug, J. (2006). A systematic review of randomized trials on the effectiveness of computer-tailored education on physical activity and dietary behaviors. Annals of Behavioral Medicine, 31, 205-223.

Locke, E.A., \& Latham, G.P. (1990). A theory of goal setting and task performance. Englewood Cliffs, NJ: Prentice Hall.

Nyman, S.R., \& Yardley, L. (in press). Usability and acceptability of a website that provides tailored advice on falls prevention activities for older people. Health Informatics Journal.

Pallant, J. (2001). SPSS survival manual: A step by step guide to data analysis using SPSS for Windows (versions 10 and 11). Maidenhead, UK: Open University Press.

Petty, R.E., \& Cacioppo, J.T. (1981). Attitudes and persuasion: Classic and contemporary approaches. Dubuque, IA: Wm. C. Brown.

Prevention of Falls Network Europe. (2006). Questionnaire to assess attitudes to balance and falling-related interventions. Retrieved March 6, 2006, from http://www.profane. eu.org/profane_documents/AFRIS.rtf

Skelton, D.A., \& Todd, C.J. (2004). What are the main risk factors for falls amongst older people and what are the most effective interventions to prevent these falls? Copenhagen, Denmark: Health Evidence Network, World Health Organization.

Speechley, M., \& Tinetti, M.E. (1991). Falls and injuries in frail and vigorous community elderly persons. Journal of the American Geriatrics Society, 39, 46-52.

Vandelanotte, C., \& De Bourdeaudhuij, I. (2003). Acceptability and feasibility of a computer-tailored physical activity intervention using stages of change: Project FAITH. Health Education Research, 18, 304-317.

Vandelanotte, C., De Bourdeaudhuij, I., Sallis, J.F., Spittaels, H., \& Brug, J. (2005). Efficacy of sequential or simultaneous interactive computer-tailored interventions for increasing physical activity and decreasing fat intake. Annals of Behavioral Medicine, 29, 138-146. 
Webb, T.L., \& Sheeran, P. (2006). Does changing behavioral intentions engender behavior change? A meta-analysis of the experimental evidence. Psychological Bulletin, 132, 249-268.

Williams, D.M., Papandonatos, G.D., Napolitano, M.A., Lewis, B.A., Whiteley, J.A., \& Marcus, B.H. (2006). Perceived enjoyment moderates the efficacy of an individually tailored physical activity intervention. Journal of Sport \& Exercise Psychology, 28, 300-309.

Yardley, L., Bishop, F.L., Beyer, N., Hauer, K., Kempen, G.I.J.M., Piot-Ziegler, C., et al. (2006). Older people's views of falls prevention interventions in six European countries. The Gerontologist, 46, 650-660.

Yardley, L., Donovan-Hall, M., Francis, K., \& Todd, C. (2007). Attitudes and beliefs that predict older people's intention to undertake strength and balance training. Journals of Gerontology. Series B, Psychological Sciences and Social Sciences, 62, P119-P125.

Yardley, L., \& Nyman, S.R. (2007). Internet provision of tailored advice on falls prevention activities for older people: A randomized controlled evaluation. Health Promotion International, 22, 122-128. 